Article

\title{
Integrated Optimization Design of Combined Cooling, Heating, and Power System Coupled with Solar and Biomass Energy
}

\author{
Lizhi Zhang, Fan Li, Bo Sun * and Chenghui Zhang \\ School of Control Science and Engineering, Shandong University, Jingshi Road 17923, Jinan 250061, China; \\ zhanglizhi0518@163.com (L.Z.); lifan1986@126.com (F.L.); zchui@sdu.edu.cn (C.Z.) \\ * Correspondence: sunbo@sdu.edu.cn; Tel.: +86-186-0531-8668
}

Received: 29 December 2018; Accepted: 17 February 2019; Published: 20 February 2019

\begin{abstract}
The combined cooling, heating, and power (CCHP) systems coupled with solar energy and biomass energy can meet the needs of island or rural decentralized and small-scale integrated energy use, which have become increasingly popular in recent years. This study presents a renewable energy sources integrated combined cooling, heating, and power (RES-CCHP) system, driven by a biogas fueled internal combustion engine (ICE) and photovoltaic (PV) panels, which is different from the traditional natural gas CCHP system. Owing to the solar energy volatility and the constraint of biomass gas production, the traditional optimization design method is no longer applicable. To improve the energetic, economic and environmental performances of the system, an integrated design method with renewable energy capacity, power equipment capacity and key operating parameters as optimization variables is proposed. In addition, a case study of a small farm in Jinan, China, is conducted to verify the feasibility of the proposed RES-CCHP system structure and the corresponding optimal operation strategy. The results illustrate that the implementation of the optimal design is energy-efficient, economical and environmentally-friendly. The values of primary energy saving ratio, annual total cost saving rate and carbon emission reduction ratio are $20.94 \%$, $11.73 \%$ and $40.79 \%$, respectively. Finally, the influence of the volatility of renewable energy sources on the optimization method is analyzed, which shows that the RES-CCHP system and the method proposed are robust.
\end{abstract}

Keywords: combined cooling; heating; and power system; renewable energy source; biogas; optimized design; multi-objective optimization

\section{Introduction}

Exploration of renewable energy sources (RES) is an important way to address the energy and environmental crisis, which has become one of the main tasks and strategic subjects for the development of the national economy and for establishing a prosperous society in the 21st century [1]. China spans a large geographical area with rural areas associated with prolonged sunshine durations and abundant renewable energy sources, such as solar and biomass resources, which have unique advantages. It is estimated that the total amount of biomass resources is approximately equivalent to 460 billion $\mathrm{kg}$ of standard coal in China each year. However, at present, most of the biomass is directly used for combustion, and the conversion efficiency is only $10 \%-20 \%$, thus resulting in serious energy waste, environmental pollution and ecological damage. Simultaneously, the rural residents in China have a prominent feature of small dispersion, and the centralized supply model is unable to alleviate the difficulties of heating supply and local pollution in the vast rural and remote areas. Therefore, the traditional electricity-based energy supply is no longer advisable. 
The combined cooling, heating and power (CCHP) system, based on the principle of energy cascade utilization, can simultaneously meet the electricity, cooling, and heating loads, which improves the energy efficiency and reduces air pollutant emissions dramatically [2-6]. Simultaneously the CCHP system provides an effective way for solar and biomass energy utilization [7-11], which especially has received widespread attention in Europe [12-14]. The choices of primary energy sources and system capacity have a significant impact on the overall performance of the CCHP system, which has been extensively studied by researchers [15-19].

Most of the current researches choose a number of algorithms for the traditional CCHP system driven by natural gas to determine the optimal system capacity. Zeng et al. [20] selected the genetic algorithm (GA) to optimize the capacity of a combined cooling, heating and power system with ground source heat pump (CCHP-GSHP), and the integrated performances of the coupling system were improved. Liu et al. [21] presented a matrix modeling approach to optimize the CCHP system with hybrid chillers, and the optimal power generation unit (PGU) capacity was determined based on the use of the enumeration algorithm, then an illustrative case study was conducted to show that the proposed method performed much better compared to traditional strategies. Wei et al. [22] adopted the non-dominated sorting genetic algorithm-II (NSGA-II) to find a set of Pareto optimal configurations of the CCHP system. Wang et al. [23] applied a particle swarm optimization algorithm (PSOA) to obtain the optimal design of the building cooling heating and power (BCHP) system.

Several documents have focused on the CCHP system with renewable energy sources. Yousefi et al. [24] proposed a CCHP system with photovoltaic/thermal (PV/T) panels, which was optimized based on the economy, energy, and emission objective functions. The GA optimization and an analytical hierarchical process were used to find the best size of the system components. Fani et al. [25] studied a solar-assisted combined cooling, heating, and power (SCCHP) system in office buildings in Iran. Noussan et al. [26] found out the optimal configuration of a biomass-fired CHP system with thermal energy storage from the economic and energetic points of view. Gazda [27] proposed a distributed energy system driven by solar energy and biogas, then analyzed the energy and environmental performance of the system. Ameri et al. [28] developed a mixed integer linear programming (MILP) model for determining the optimal capacity of CCHP systems with photovoltaic systems so that the initial and operating costs of the energy supply system were minimized. Ebrahimi et al. [29] designed a hybrid-CCHP system that consisted of a basic CCHP system and a solar collector for a residential building in five different climates. The maximum rectangle method was applied to identify the optimal size of the prime mover. Ju et al. [30] compared the performance of a CCHP and renewable energy-based hybrid energy system driven by distributed energy resources (DERs CCHP) and a CCHP system driven by natural gas (NG CCHP), which indicated that the former had better operational performance. Li et al. [31] applied the preference-inspired coevolutionary algorithm (PICEA-g) to the configuration of the CCHP system with renewable energies.

Owing to the volatility and intermittency of renewable energy sources and the time-varying load, a source-load mismatch problem emerges, whereby the addition of RES makes the CCHP system structure and energy flow more complicated. Most of the optimization design methods only optimize the capacity of the PGU while primary energy sources have not been optimized, which is applicative for the natural gas-driven CCHP system to achieve the optimal targets since natural gas is sufficient and stable. However, biomass energy is completely different from natural gas since the utilization of biomass energy is affected by daily production, which is a constraint for optimal design. Therefore, the current optimization design of CCHP system is rendered not applicable.

This study presents a RES-CCHP system driven by a biogas-fueled internal combustion engine (ICE) and photovoltaic (PV) panels. Separate optimization of PV and PGU, would not elicit the best results. Thus, comprehensive consideration of renewable energy and load characteristics, four-decision variables (the capacity of the PGU, the number of PV panels, the on-off coefficient of PGU, and the ratio of electric cooling to cooling load) were selected to be optimized in order to achieve collaborative optimization. A multi-objective integrated optimization model that maximizes the annual total cost 
saving rate (ATCSR), primary energy saving ratio (PESR), and carbon emission reduction ratio (CERR), and considers the off-design performance of the PGU, is proposed. The GA is adopted to determine the capacity and key operation parameters of the RES-CCHP system. In addition, a case study of a small farm in Jinan, China is conducted to ascertain the feasibility of the proposed RES-CCHP system structure and the corresponding optimization design method.

The remainder of this study is organized as follows: Section 2 describes the structure and energy flows of the RES-CCHP system. Section 3 presents the optimization model. Results of the simulation and optimization are given and analyzed in Section 4 . The conclusions are summarized in the last section.

Compared with existing approaches, the main contributions of this paper are summarized as follows:

(1) Considering the fluctuation of solar energy and the limitation of biomass energy, the PGU will frequently operate in a variable operating condition. This paper analyzed off-design performance of the PGU, and the daily biogas production was added into the optimization model as a constraint condition, so that the obtained equipment capacity can be more guaranteed to operate in an efficient operation area and the renewable energy has higher utilization.

(2) The capacity of the PGU, the number of PV panels, the on-off coefficient of PGU, and the ratio of electric cooling to cooling load were collectively optimized to improve the energetic, economic and environmental performances of the system.

(3) The influence of the volatility of renewable energy sources on the design results and system performance is analyzed to prove the proposed RES-CCHP system and the design method are robust.

\section{System Description}

\subsection{System Design}

The RES-CCHP system consists of PGU, PV panels, a heat recovery unit, an absorption chiller (AC), an electric chiller (EC), a heat exchanger, and an auxiliary boiler, which is shown in Figure 1. Correspondingly, the system design is based on the following points:

1. The electricity subsystem consists of PV, power grid (PG) and PGU by biogas. The PV will generate low power when the illumination is low, and the deficiency is thus supplemented by biomass power generation. Biomass reserves are abundant and biomass power generation is more controllable. This can be used with noncontrollable photovoltaic systems as an energy mix to improve system stability. The electricity generated can meet the electrical demand and drive the EC to meet the cooling demand. The RES-CCHP system is connected to grid so that the system can sell the surplus electricity to the PG or purchase the cheap power.

2. The selection of the PGU has a decisive influence on the performance of the entire system. Turbine engines (TEs) and internal combustion engines (ICEs) are two types of power equipment normally used in current CCHP systems. In view of their capacities at a level of tens of kilowatts, ICEs are superior to TEs in terms of efficiency and cost, so a small biogas-fueled ICE is selected as a power plant for the RES-CCHP system.

3. Because of the small amount of recovered waste heat in the case of a small ICE, the single-effect, hot water absorption chiller is adopted. In addition, a water recycling subsystem is employed to recover waste heat from jacket water (JW) and exhaust gas (EXH) so that hot water is produced for heating and driving the absorption chiller, and the excess heat is provided for biogas fermentation to maintain a constant fermentation temperature and ensure efficient biogas production. When the system waste heat is insufficient, shortfall heat can also be supplemented by the biogas-fueled boiler.

4. As the coefficient of performance (COP) of single-effect hot water absorption chiller is low, an EC with an increased performance coefficient is used to achieve hybrid cooling. 


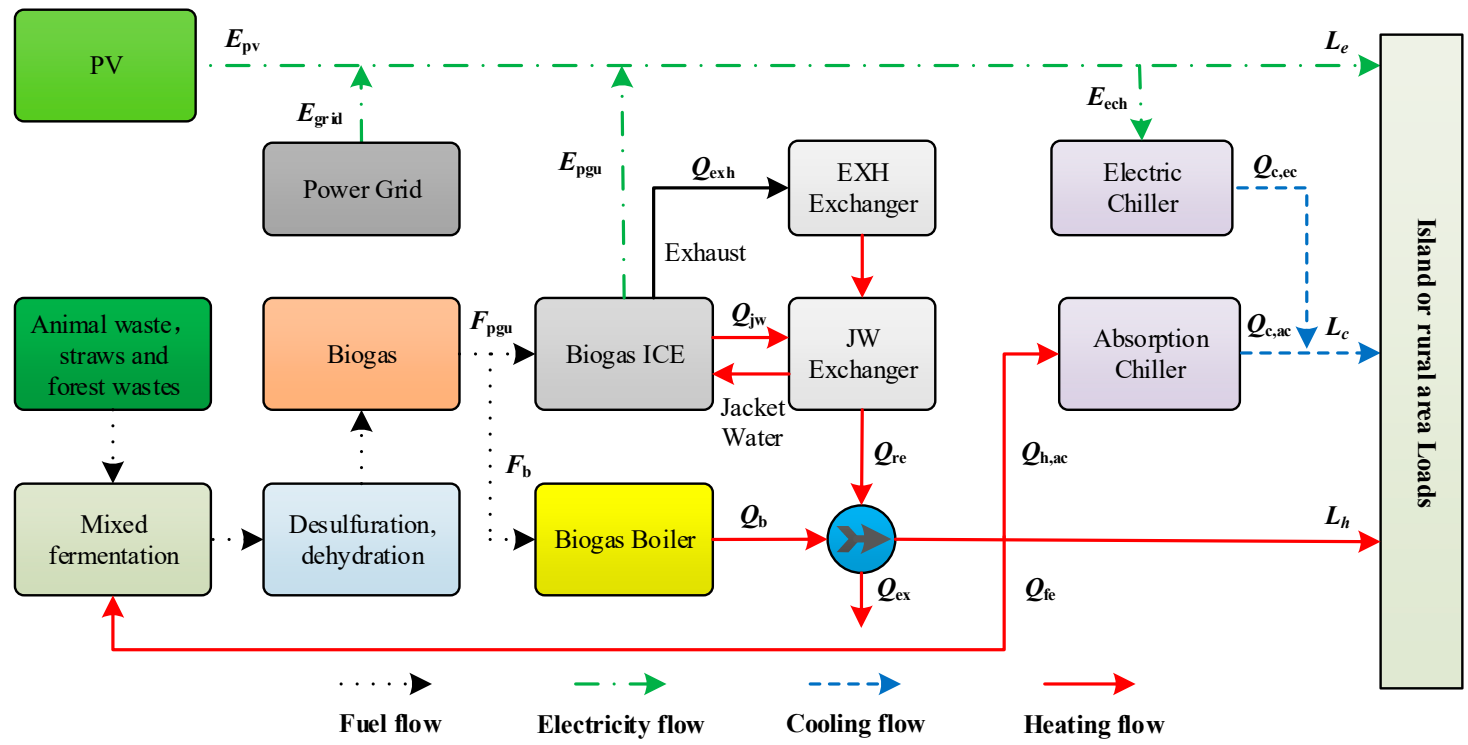

Figure 1. Structure and energy flows of renewable energy sources integrated combined cooling, heating, and power (RES-CCHP) system.

Considering that the system is designed according to the island and rural energy supply conditions, the dependence and impact on the PG should be reduced as much as possible, while the RES-CCHP system operates in a grid-connected mode. Therefore, the system follows the electric demand.

\subsection{Energy Flow Analysis}

The first step of the system design is to analyze its energy flow. In Figure 1, $E_{p v}$ and $E_{p g u}$ respectively represent the electricity generated by the PV and PGU, while $E_{g b}$ and $E_{g s}$ respectively represent the electricity bought from the grid and sold electricity. $E_{e c}$ is the input power of the electric chiller, and $L_{e}, L_{h}$, and $L_{c}$, represent the user demands for electricity, heating, and cooling, respectively.

The electrical energy balance is expressed as:

$$
L_{e}(t)+E_{e c}(t)=E_{p v}(t)+\delta(t) E_{g b}(t)+E_{p g u}(t)-(1-\delta(t)) E_{g s}(t),
$$

where $\delta(t)$ represents the state variable of interaction with the power grid, i.e., whereby the number 1 indicates that the RES-CCHP system purchases electricity from PG in period $t$, whereas 0 indicates that the system sells electricity to PG in period $t$.

The fuel consumption of the PGU is expressed as:

$$
F_{p g u}(t)=\frac{E_{p g u}(t)}{\eta_{e, p g u}(t)}
$$

where $\eta_{e, p g u}$ is the electrical efficiency of the PGU, which are both affected by the part-load ratio (PLR).

Meanwhile, the primary energy consumption of the PG is:

$$
F_{p g}(t)=\frac{E_{g r i d}(t)}{\eta_{e, p g} \eta_{d, p g}}
$$

where $\eta_{e, p g}$ and $\eta_{d, p g}$ are the efficiencies of the electricity generation and distribution of the PG, respectively.

Correspondingly, the heating balance of the RES-CCHP system is:

$$
L_{h}(t)+Q_{h, a c}(t)+Q_{e x}(t)+Q_{f e}(t)=Q_{r e}(t)+Q_{b}(t),
$$


where $Q_{h, a c}$ is the input power of absorption chiller, $Q_{e x}$ is heat loss of the system, $Q_{f e}$ is the heat required for biogas fermentation, $Q_{r e}$ represents the recovered waste heat from the PGU, and $Q_{b}$ represents the heating power from the auxiliary boiler.

The recovered waste heat from the PGU in period $t$ can be expressed as:

$$
\left\{\begin{array}{l}
Q_{r e}(t)=Q_{j w}(t)+Q_{e x h}(t) \\
Q_{j w}(t)=G_{p g u}(t)\left(1-\eta_{e, p g u}\right) \times f_{j w}(t) \times \eta_{j w, h e} \\
Q_{e x h}(t)=G_{p g u}(t)\left(1-\eta_{e, p g u}\right) \times f_{e x h}(t) \times \eta_{e x h, h e}
\end{array},\right.
$$

where $Q_{j w}$ and $Q_{e x h}$ are the jacket water heat and the exhaust heat, respectively, and $\eta_{j w}, h e$ and $\eta_{\text {exh,he }}$ are the heat exchange efficiencies of the jacket water and exhaust, respectively.

The input power of the auxiliary gas boiler at time $t$ can be expressed as:

$$
F_{b}(t)=Q_{b}(t) / \eta_{b}
$$

where $\eta_{b}$ is the thermal efficiency of the biogas boiler.

Thus, the biogas consumption of the RES-CCHP system is:

$$
F_{g a s}(t)=F_{p g u}(t)+F_{b}(t) .
$$

The cooling balance of the CCHP system is:

$$
L_{c}(t)=Q_{c, a c}(t)+Q_{c, e c}(t),
$$

where $Q_{c, a c}$ and $Q_{c, e c}$ are the cooling output of the absorption and electric chillers, respectively.

The cooling capacity of the absorption chiller can be expressed as follows:

$$
Q_{a c, c}(t)=Q_{h, a c}(t) \times C O P_{a c},
$$

where $C O P_{a c}$ is the coefficient of performance of the absorption chiller.

The electricity consumption of the electric chiller is given as:

$$
E_{e c}(t)=\frac{Q_{c, e c}(t)}{C O P_{e c}}
$$

where $C O P_{e c}$ is the $\mathrm{COP}$ of the electric refrigerator.

The electric cooling ratio $\alpha$ can be expressed as:

$$
\alpha=\frac{Q_{c, e c}(t)}{Q_{c, a c}(t)+Q_{c, e c}(t)} .
$$

\subsection{Off-Design Performance of the PGU}

PGU is the core power equipment of the system, whose off-design characteristics are obvious owing to the fluctuation of load and renewable energy sources, and determine the entire system operation. The off-design performance is simulated by the American Society of Heating, Refrigerating and Air-Conditioning Engineers (ASHRAE) data for a naturally aspirated ICE, as shown in Table 1 [32].

In the table, $\eta_{t h, i c e}$ and $\eta_{e, e g}$ denote the thermal efficiency of the ICE and the electrical efficiency of the electrical generator (EG), respectively. Therefore, the electrical efficiency of the PGU can be expressed as:

$$
\eta_{e, p g u}=\eta_{t h, i c e} \times \eta_{e, e g}
$$


According to the above data, the electrical efficiency of the PGU at different PLR can be obtained as follows:

$$
\eta_{e, p g u}(t)=-0.3569 \times r(t)^{4}+0.8424 \times r(t)^{3}-1.106 \times r(t)^{2}+0.8839 \times r(t)+0.0003822,
$$

where $r(t)$ is the part-load ratio of the PGU.

Equivalently, $f_{j w}, f_{e x h}$, and $f_{e x}$, correspond to the proportion coefficients of the total waste heat of the unit from the jacket water, exhaust gas, and heat loss, respectively, which satisfy the following relationship:

$$
f_{j w}+f_{e x h}+f_{e x}=1
$$

The heat coefficient of the jacket water can also be obtained based on data fitting, as shown in Equation (15):

$$
f_{j w}(t)=0.3488 \times r(t)^{4}-1.214 \times r(t)^{3}+1.249 \times r(t)^{2}-0.5154 \times r(t)+0.5631 .
$$

The heat coefficient of exhaust gas is shown in Equation (16):

$$
f_{\operatorname{exh}}(t)=0.3276 \times \exp \left(-\left(\frac{r(t)-0.7451}{1.164}\right)^{2}\right)+0.01486 \times \exp \left(-\left(\frac{r(t)-0.312}{0.1055}\right)^{2}\right)+0.06028 \times \exp \left(-\left(\frac{r(t)-0.03373}{0.2108}\right)^{2}\right) .
$$

Table 1. Performance factors of naturally aspirated internal combustion engine (ICE).

\begin{tabular}{cccccc}
\hline PLR & $\eta_{p e}$ & $\eta_{p t}$ & $f_{j w}$ & $f_{\text {exh }}$ & $\boldsymbol{F}_{\boldsymbol{e x}}$ \\
\hline 0.0000 & 0.0000 & 0.0000 & 0.5628 & 0.2764 & 0.1608 \\
0.1000 & 0.1020 & 0.7700 & 0.5227 & 0.2955 & 0.1818 \\
0.2000 & 0.1809 & 0.7800 & 0.5031 & 0.3006 & 0.1963 \\
0.3000 & 0.2250 & 0.8200 & 0.4903 & 0.3097 & 0.2000 \\
0.4000 & 0.2637 & 0.8400 & 0.4865 & 0.3108 & 0.2027 \\
0.5000 & 0.2871 & 0.8600 & 0.4861 & 0.3125 & 0.2014 \\
0.6000 & 0.3085 & 0.8750 & 0.4892 & 0.3237 & 0.1870 \\
0.7000 & 0.3184 & 0.8850 & 0.4818 & 0.3285 & 0.1898 \\
0.8000 & 0.3184 & 0.9000 & 0.4745 & 0.3285 & 0.1971 \\
0.9000 & 0.3039 & 0.9100 & 0.4507 & 0.3169 & 0.2324 \\
1.0000 & 0.2886 & 0.9200 & 0.4336 & 0.3147 & 0.2517 \\
\hline
\end{tabular}

\section{Optimization Model}

\subsection{Objective Function}

The multi-objective (MO) function, including the environment, economic, and energy objectives, is used to evaluate the overall performance of the RES-CCHP system, compared to the separated production (SP) system. In the SP system, the PG is employed to supply the electricity, and the electric chiller and gas boiler are used to produce the cooling and heating energy, respectively.

\subsubsection{Energy Objective}

It is vital for RES-CCHP to improve the ratio of the energy usage which is the basic criterion of the newly developed system. PESR is the ratio of the energy-saving of the RES-CCHP system compared to the SP system, which can be illustrated as:

$$
P E S R=\frac{F_{S P}-F_{C C H P}}{F_{S P}},
$$

where $F_{S P}$ is the yearly energy consumption of the SP system, and $F_{C C H P}$ is the energy consumption of the RES-CCHP system in a year. 
The energy consumption of the RES-CCHP system is composed of the amount of biogas consumption of the PGU and the boiler and the consumption of the grid. Thus, $F_{\mathrm{CCHP}}$ can be calculated in accordance to:

$$
\left\{\begin{array}{l}
F_{C C H P}=F_{C C H P, g r i d}+F_{C C H P, g a s} \\
F_{C C H P, g r i d}=\sum_{t=1}^{8760} \frac{E_{C C H P, g r i d}(t) \times T}{\eta_{e, p g} \eta_{d, p g} v} \\
F_{C C H P, g a s}=\sum_{t=1}^{8760} \frac{F_{p g u}(t)+F_{b}(t)}{v} \times T
\end{array},\right.
$$

where $F_{C C H P, g r i d}$ is the prime energy consumption of the grid, $F_{C C H P, g a s}$ is the biogas consumption of the PGU and the boiler, and $T$ and $v$ are the time interval and standard coal conversion factor $(8.13 \mathrm{kWh} / \mathrm{kg})$, respectively.

In the SP system, the primary energy is mainly consumed by the grid and auxiliary boilers, so FSP can be calculated in accordance to:

$$
F_{S P}=\sum_{t=1}^{8760}\left(\frac{E_{S P, g r i d}(t)}{\eta_{e, p g} \eta_{d, p g} v}+\frac{G_{S P, b}(t)}{\eta_{S P, b} v}\right) \times T,
$$

where $G_{S P, b}$ is the heating power from the auxiliary boiler in the SP system.

\subsubsection{Economy Objective}

Economy is a prerequisite for the popularization and application of a large area of the system. The full life cycle cost of the system is adopted in the economy objective, which includes the investment cost, the maintenance cost, and the operation cost of the system equipment. According to the life cycle cost analysis (LCCA), it is converted into the annual cost of the system. The annual total cost saving rate (ATCSR) is used as the economy objective and expressed as [20,33]:

$$
A T C S R=\frac{C_{S P}-C_{C C H P}}{C_{S P}}
$$

where $C_{C C H P}$ and $C_{S P}$ are the annual costs of the RES-CCHP system and the annual cost of the SP system, respectively.

The $C_{C C H P}$ and $C_{S P}$ can be described as:

$$
\left\{\begin{array}{l}
C_{\mathrm{CCHP}}=C_{C C H P, E Q}+C_{C C H P, O M}+C_{C C H P, E C} \\
C_{S P}=C_{S P, E Q}+C_{S P, O M}+C_{S P, E C}
\end{array},\right.
$$

where $C_{C C H P, E Q}, C_{C C H P, O M}$ and $C_{C C H P, E C}$ are the annual investment cost, maintenance cost and operation expenses of the RES-CCHP system, respectively, while $C_{S P, E Q}, C_{S P, O M}$ and $C_{S P, E C}$ are the annual investment cost, maintenance cost and operation expenses of the SP system, respectively.

The values of $C_{C C H P, E C}, C_{C C H P, E Q}$ and $C_{C C H P, O M}$ can be calculated as:

$$
\left\{\begin{array}{l}
C_{C C H P, E C}=\sum_{t=1}^{8760}\left\{P_{g b}(t) E_{C C H P, g b}(t)-P_{g s}(t) E_{C C H P, g s}(t)\right\} \times T+C_{g a s} \\
C_{C C H P, E Q}=C_{C C H P, I N} R \\
C_{C C H P, O M}=\sigma C_{C C H P, I N} \\
C_{g a s}=\sum_{t=1}^{8760}\left\{G_{p g u}(t)+G_{b}(t)\right\} \times T \times P_{g a s}
\end{array},\right.
$$

where $P_{g b}, P_{g s}$, are the purchase and sale prices of the grid, respectively, $C_{g a s}$ and $C_{C C H P, I N}$, are the annual fuel and total investment costs, respectively, $R$ is the capital recovery factor, $P_{\text {gas }}$ is the price of biomass gas, $\sigma$ is the system maintenance cost coefficient. 
The values of $C_{S P, E C}, C_{S P, E Q}$ and $C_{S P, O M}$ can be calculated as:

$$
\left\{\begin{array}{l}
C_{S P, E C}=\sum_{t=1}^{8760} P_{g b}(t) E_{S P, g r i d}(t) T \\
C_{S P, E Q}=C_{S P, I N} R \\
C_{S P, O M}=\sigma C_{S P, I N}
\end{array},\right.
$$

where $E_{S P, g b}$ denotes the purchase power from the grid at time $t$, and $C_{S P, I N}$ is the total investment cost of the SP system.

The capital recovery factor, $R$, can be defined as:

$$
R=\frac{r(1+r)^{k}}{(1+r)^{k}-1}
$$

where $r$ is the rate of interest and $k$ is the service life period of each component. In this study, the values of $r$ and $k$ are 0.08 and 15 , respectively.

\subsubsection{Environment Objective}

Environmental issues are hot issues in the context of the social development, which is an important factor in the development of the RES-CCHP system. The carbon emission reduction ratio (CERR) is expressed as $[33,34]$ :

$$
C E R R=\frac{C E_{S P}-C E_{C C H P}}{C E_{S P}},
$$

where $C E_{C C H P}$ and $C E_{S P}$ are the carbon dioxide emissions of the RES-CCHP and SP systems, respectively.

The carbon dioxide emission of the RES-CCHP can be calculated as:

$$
C E_{C C H P}=\sum_{t=1}^{8760}\left(E_{C C H P, \text { grid }}(t) \mu_{\text {grid }}+E_{C C H P, \text { gas }}(t) \mu_{\text {gas }}\right) \times T,
$$

where $\mu_{\text {grid }}$ and $\mu_{\text {gas }}$ are the emission factors of the grid and biomass gas, respectively.

The carbon dioxide emission of the SP system can be calculated as:

$$
C E_{S P}=\sum_{t=1}^{8760}\left(E_{S P, g b}(t) \mu_{\text {grid }}+G_{S P, b}(t) \mu_{n g}\right) \times T,
$$

where $\mu_{n g}$ is the emission conversion factor of natural gas.

Thus, the optimization objective function of the RES-CCHP system can be defined as:

$$
\max M O=\omega_{1} P E S R+\omega_{2} A T C S R+\omega_{3} C E R R,
$$

where $0 \leq \omega_{1}, \omega_{2}, \omega_{3} \leq 1$, and $\omega_{1}+\omega_{2}+\omega=1$. In this case, $\omega_{1}, \omega_{2}, \omega_{3}$, are the corresponding weight coefficients. Their values respectively represent the importance of the energy, economic, and environmental influences, respectively. To attain the best performance in the case of the RES-CCHP system, the objective is to maximize MO.

The weight coefficients represent the weight of each sub-objective in the optimization solution. The value of each weight coefficient has an important influence on the result of the optimal configuration. In this study, the judgment matrix method was used to classify the three sub-objectives according to their importance in the optimization configuration. In order to maximize the advantage of the system in terms of its energy saving potential, the energy indicator is selected as the first-level indicator in the optimization configuration. The economic indicator represents the economic performance of the joint supply system. This indicator has a greater impact on application promotion and serves as the second-level indicator for optimal allocation. The environmental protection index 
represents the reduction in the operation of the CCHP system. Compared to the SP system, the CCHP system has a clear advantage in terms of pollutant emissions, and so, it is used as a third-level indicator. The weight coefficient corresponding to each index was determined by constructing a judgment matrix $[35,36]$.

\subsection{Optimization Variable}

The RES-CCHP system contains a variety of equipment types, and the selection of the optimization variables should thus follow the principles of independence, importance, and decisiveness.

The equipment capacity configuration and optimization operating parameters to be optimized in this article include the following sections.

\subsubsection{PV Capacity}

As an important source of electrical energy in this system, the capacity of the PV component has a great influence on the system performance. Considering that a photovoltaic battery group is composed of a certain number of photovoltaic battery modules in series and parallel, the relationship between its capacity and the capacity of a single module can be expressed as:

$$
N_{p v}=M \times N_{s, p v}
$$

where $N_{p v}$ is the capacity of PV, $M$ is the number of photovoltaic cell modules, and $N_{s, p v}$ is the capacity of a single photovoltaic cell module.

Therefore, the number of photovoltaic cell modules represents the capacity of the PV. For general buildings, photovoltaic cells are usually placed in open space with good lighting conditions, such as the roof of a building. However, since the photovoltaic cell modules need to occupy a large area, the available area must be considered as a constraint in the configuration process for the capacity of the photovoltaic cell. The relationship between the PV capacity and its usable area can be expressed as:

$$
\left\{\begin{array}{l}
S_{p v}=M \times S_{s, p v} \\
S_{p v} \leq S_{\max }
\end{array},\right.
$$

where $S_{p v}$ is the area of $\mathrm{PV}, S_{s, p v}$ is the area of a single $\mathrm{PV}$, and $S_{\max }$ is the available area.

\subsubsection{Capacity and Minimum Load Coefficient of PGU}

PGU is the most important power equipment in this integrated power supply system, and many parameters of other equipment types, such as the capacities of the auxiliary boiler, absorption chiller, and electric chiller, are determined by the capacity of the PGU. Therefore, the capacity of PGU should be an important variable in the optimal configuration of the system. Meanwhile, in order to increase the operating efficiency of the PGU, the generator set should not be operated at low-loads for too long. Thus, $N_{p g u}$ and $\theta$ are selected as the optimization variables.

\subsubsection{Electric Cooling Ratio}

In general, the COP of an electric chiller is greater than that of an absorption chiller. Therefore, setting up the electric chiller in the system not only provides supplementary cooling when the absorption chiller is insufficient for cooling, but can also improve the operating efficiency of the RES-CCHP system by rationally setting the electric cooling ratio. Thus, $\alpha$ is selected as the optimization variable. 
In combination with the above, $N_{p v}, N_{p g u}, \theta$, and $\alpha$ were chosen in this study. These four variables were solved by the genetic algorithm to improve the comprehensive performance of the RES-CCHP system. However, when the values of $\theta$ and $\alpha$ are not constant, the operational strategy would become more complex, which is difficult to achieve in the real application. Therefore, the electric cooling ratio and the minimum load factor of PGU are fixed to simplify the operation strategy in this study.

\subsection{Constraints}

Considering the operational status of the RES-CCHP system, the optimization process should both satisfy the equality constraints expressed by Equations (1)-(11) and the following inequality constraints:

$$
\begin{gathered}
0 \leq N_{p q u} \leq N_{p g u, \text { max }}, \\
0 \leq N_{p v} \leq N_{p v, \text { max }}, \\
0 \leq \alpha \leq 1, \\
0.2 \leq \theta \leq 1, \\
0 \leq F_{p q u, g a s}+F_{b, g a s} \leq F_{\text {gas }},
\end{gathered}
$$

where $N_{p g u, m a x}$ and $N_{p v, \max }$ are the upper capacity bounds of the PGU and PV, respectively, $F_{p g u, g a s}$ and $F_{b, g a s}$ are the amount of biomass gas consumed by the PGU and the boiler, respectively, and $F_{g a s}$ is the daily production of the biomass gas. Equations (33) and (34) ensure that $N_{p g u}$ and $N_{p v}$ are within a reasonably feasible range.

Under normal circumstances, the configuration capacity of PGU and the electric chiller in the RES-CCHP system should not exceed the maximum electricity and cooling load values. Therefore, the maximum value of the electricity and cooling load is selected as the upper limit of the capacity configuration of PGU and the electric chiller. The capacity of PV is limited by the site area for the layout. The upper limit of the capacity of PV is determined by the area of the layout site. The daily production of the biogas is determined by the biomass energy available to users. From Table 1, it can be seen that when the electrical load rate is less than $20 \%$, the power generation efficiency of PGU is lower than $14.11 \%$. Therefore, in order to ensure the efficient operation of the PGU, the lower limit of the minimum load rate of the PGU is set to 0.2 .

\subsection{Optimization Algorithm}

Since the CCHP system is a complex energy system that can operate at various operating conditions, it is difficult to optimize it using simple mathematical methods. Therefore, this study adopted a genetic algorithm to solve the multi-objective optimization model. The operating process of the solution method is shown in Figure 2. First, relevant parameters need to be set in advance, including the GA parameters, cost parameters, building load, and performance parameters of the RES-CCHP and SP systems. The optimization variables were coded in binary form. Then, the fitness of the objective function was calculated. The searching process will not stop until the convergence condition is met. After that, the optimization results will be obtained, including $N_{\mathrm{pv}}, N_{\mathrm{pgu}}, \theta$, and $\alpha$. The calculation process was implemented in MATLAB. 


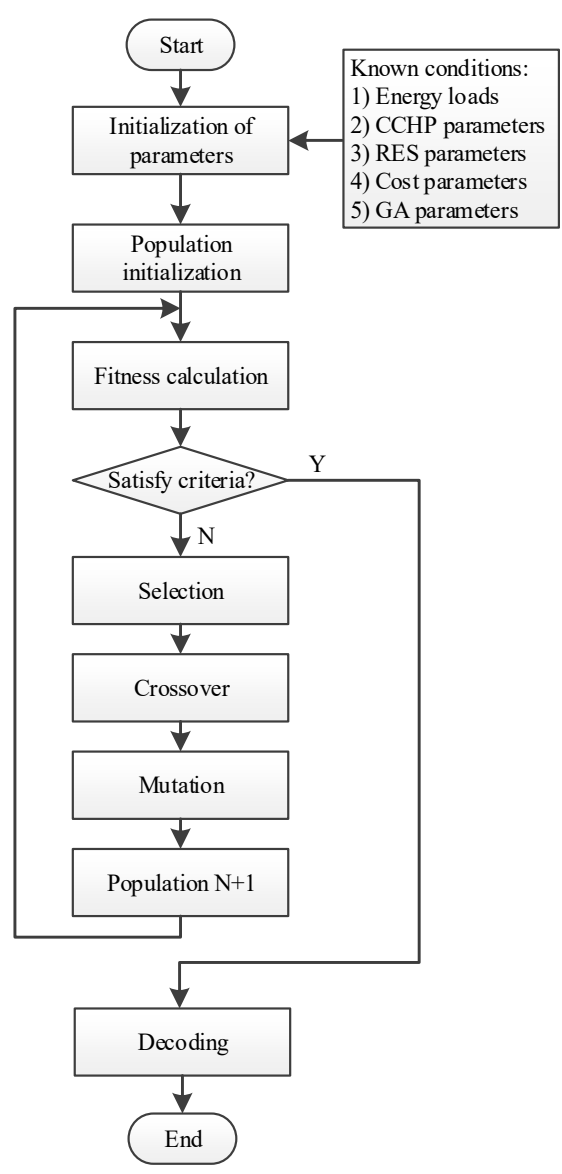

Figure 2. Flow diagram of the execution of the genetic algorithm (GA).

\section{Case Study}

\subsection{Building Load Simulations}

Farms are typical end-users of the RES-CCHP system, with stable annual electric, heating, and cooling demands. In order to verify the correctness of the proposed optimal configuration method, this study considered a suburban farm in Jinan, China, as an example for simulating the year-by-year cold, heat, and electrical loads of the farm's building, based on its energy analysis software eQUEST (DOE-2.2, LBNL, Berkeley, CA, USA), as shown in Figures 3-5. The situation of the farm and biogas are shown in Tables 2 and 3, respectively. This study establishes a photovoltaic cell module model using the TRNSYS software simulation platform. The annual output power of the PV in the climate environment of Jinan, in China is shown in Figure 6.

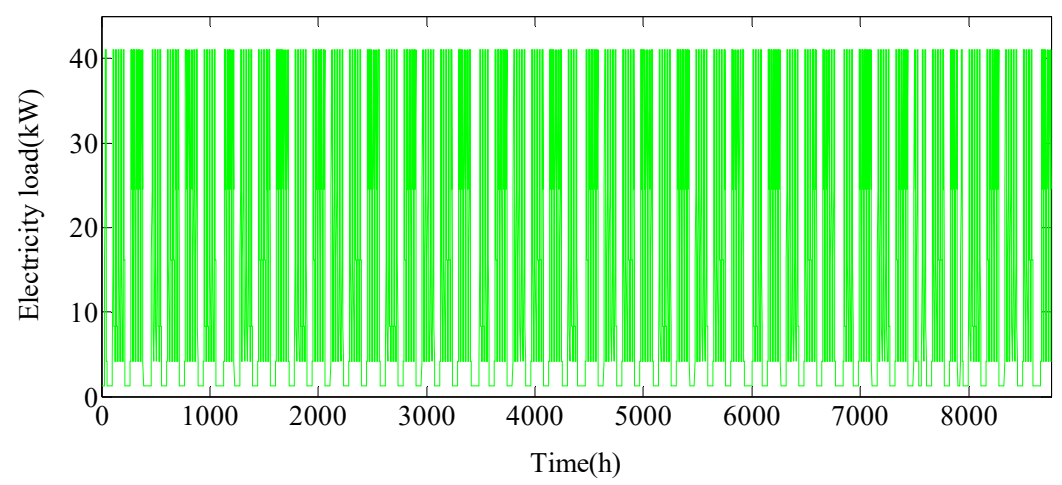

Figure 3. Annual electricity load of building. 


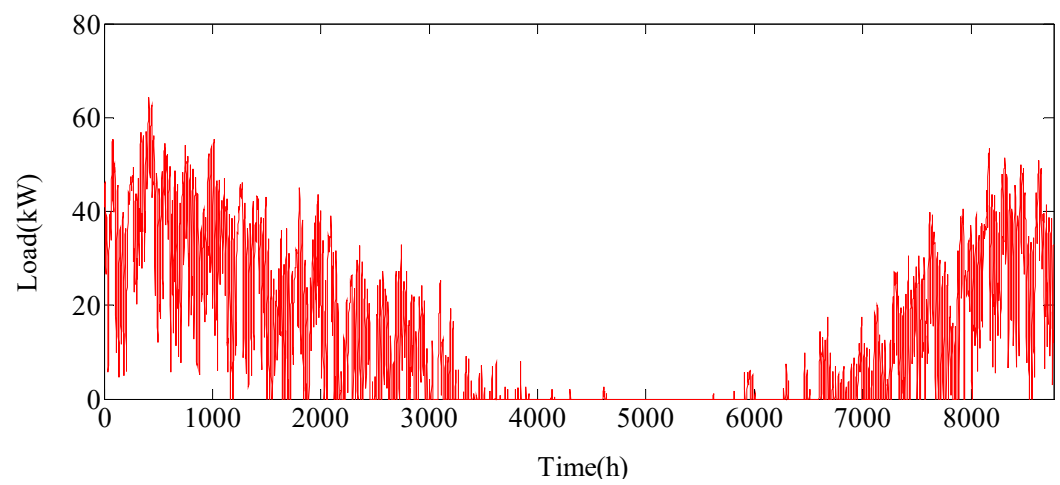

Figure 4. Annual heating load of building.

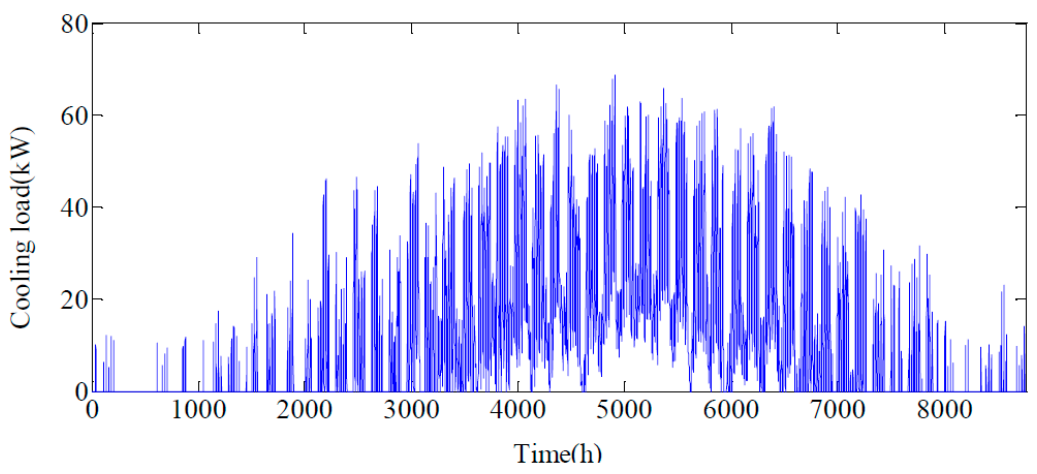

Figure 5. Annual cooling load of building.

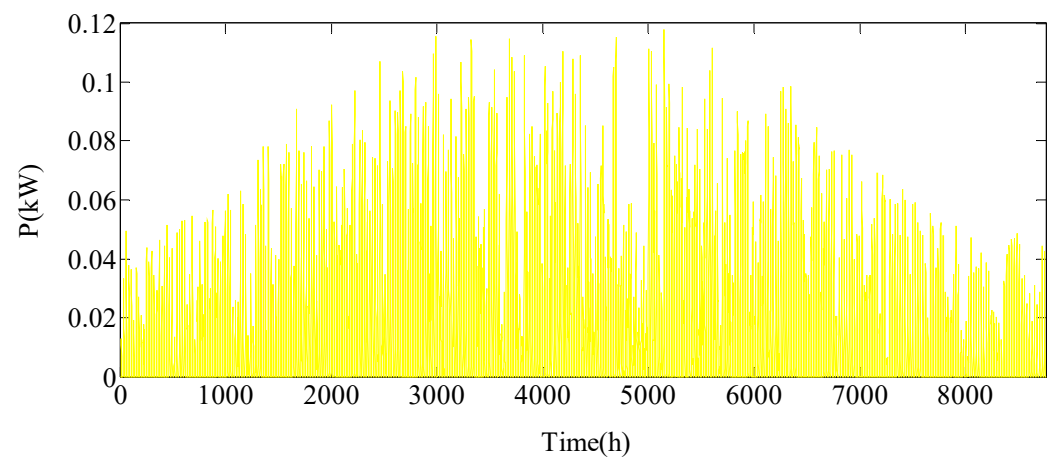

Figure 6. Annual output of single photovoltaic plane.

Table 2. Description of the simulated building.

\begin{tabular}{cc}
\hline Content & Data \\
\hline Height & $3.2 \mathrm{~m}$ \\
Lights & $13 \mathrm{~W} / \mathrm{m}^{2}$ \\
Winter setting temperature & $22^{\circ} \mathrm{C}$ \\
Summer setting temperature & $24^{\circ} \mathrm{C}$ \\
People & $0.17 \mathrm{people} / \mathrm{m}^{2}$ \\
Electric equipment & $21 \mathrm{~W} / \mathrm{m}^{2}$ \\
\hline
\end{tabular}

Table 3. Production information of the biogas.

\begin{tabular}{cc}
\hline Content & Data \\
\hline Fermentation temperature & $37^{\circ} \mathrm{C}$ \\
Methane content & $58.2 \%$ \\
Daily production & $190 \mathrm{~m}^{3} / \mathrm{d}$ \\
Biogas flow ( PGU in $30 \mathrm{~kW})$ & $18.6 \mathrm{~m}^{3} / \mathrm{h}$ \\
\hline
\end{tabular}


In accordance to Figures 3-5, the time distribution characteristics of the building load can be obtained.

- The loads of the building have obvious seasonal characteristics. According to the time distributions of electric, cooling, and heating loads, it can be divided into three typical seasonal load conditions corresponding to the winter, summer, and transition season.

- The quarterly alternation exhibits no significant effect on the distribution of electric loads, but the electric load variation is associated with distinct time periods. The specific performance is assessed assuming that the electric load remains unchanged during the working hours, and the electric load is significantly reduced during the nonworking hours and holidays.

- The heating load is mostly increased in the winter and transition seasons, and there is no heating load demand in the summer.

It should be pointed out that in order to avoid repeated load calculations, the electrical load of the building simulated in this study only included electricity consumed by lighting and electric machinery and does not include the electric energy load generated by driving the electric refrigerator.

\subsection{Simulation Parameter Settings}

Known conditions, such as the characteristic parameters of RES-CCHP and SP system, are shown in Table 4. The SP system, which serves as a reference in the optimized configuration only contains the electric chiller and the auxiliary boiler, and its capacity could be determined according to the maximum electric and thermal load throughout the year.

Table 4. Characteristic parameters of the renewable energy sources integrated combined cooling, heating, and power (RES-CCHP) system and SP system.

\begin{tabular}{cccc}
\hline System & Parameters & Symbol & Values \\
\hline \multirow{4}{*}{ RES-CCHP system } & COP of electric chiller & $C O P_{E C}$ & 4.0 \\
& COP of absorption chiller & $C O P_{A C}$ & 1.2 \\
& Efficiency of boiler & $\eta_{b}$ & 0.82 \\
& Efficiency of grid distribution & $\eta_{d}$ & 0.92 \\
& Efficiency of grid electricity generation & $\eta_{e}$ & 0.35 \\
\hline \multirow{5}{*}{ SP system } & Rated capacity of electric chiller & $Q_{E C, R C}$ & $69 \mathrm{~kW}$ \\
& Rated capacity of boiler & $Q_{b, R C}$ & $65 \mathrm{~kW}$ \\
& COP of electric chiller & $C O P_{S P, E C}$ & 4.0 \\
& Efficiency of boiler & $\eta_{S P, b}$ & 0.82 \\
\hline
\end{tabular}

Equipment costs of RES-CCHP and SP systems are listed in Table 5. In this study, biomass gas was used as the primary energy in the system. Compared with natural gas, various pollutant emission coefficients are different, as shown in Table $6[31,37]$.

Table 5. Unit prices of used equipment.

\begin{tabular}{ccc}
\hline Item & Value & Lifetime (Year) \\
\hline PGU & $3800(¥ / \mathrm{kW})$ & 15 \\
Absorption chiller & $1280(¥ / \mathrm{kW})$ & 15 \\
Electric chiller & $970(¥ / \mathrm{kW})$ & 15 \\
Boiler & $1387(¥ / \mathrm{kW})$ & 15 \\
PV modules & $1200(¥ /$ piece $)$ & 15 \\
\hline
\end{tabular}

Table 6. Pollutant emission coefficients.

\begin{tabular}{cccc}
\hline \multirow{2}{*}{ Item } & \multicolumn{3}{c}{ Emission Coefficients $(\mathbf{g} / \mathbf{( k W \cdot h ) )}$} \\
\cline { 2 - 4 } & Natural Gas & Grid & Biogas \\
\hline $\mathrm{CO}_{2}$ & 203.74 & 326.37 & 196 \\
$\mathrm{SO}_{2}$ & 0.011 & 1.8 & 0.031 \\
$\mathrm{NO}_{\mathbf{x}}$ & 0.202 & 1.6 & 0.015 \\
\hline
\end{tabular}


The electricity price has a significant influence on the economic efficiency of the system. Different electricity prices are adopted in different regions, which would affect the operation of the system and the capacity allocation. This study fully considered the electricity price structure of Jinan in the test site and adopts three types of electricity price structures: peak, valley, and flat. The time-of-use price policy is currently applied in Jinan, China, where three price stages matched with peak-flat-valley value periods. The time-of-use price and timetable are shown in Table 7 [22,38].

Table 7. Time-of-use electricity prices.

\begin{tabular}{cccc}
\hline Type & $\begin{array}{c}\text { Peak Value (8:00-11:00) } \\
(\mathbf{1 8 : 0 0 - 2 3 : 0 0 )}\end{array}$ & $\begin{array}{c}\text { Flat Value (7:00-8:00) } \\
\mathbf{( 1 1 : 0 0 - 1 8 : 0 0 )}\end{array}$ & $\begin{array}{c}\text { Valley Value } \\
\mathbf{( 2 3 : 0 0 - 7 : 0 0 )}\end{array}$ \\
\hline Electricity price $/ ¥ /(\mathrm{kWh})$ & 1.3458 & 0.9003 & 0.4748 \\
Subsidized price $/ ¥ /(\mathrm{kWh})$ & 0.62 & 0.36 & 0.12 \\
\hline
\end{tabular}

The weight coefficients corresponding to each index are shown in Table 8.

Table 8. Weight coefficients.

\begin{tabular}{cccc}
\hline Weight Coefficient & $\omega_{1}$ & $\omega_{2}$ & $\omega_{3}$ \\
\hline Value & 0.637 & 0.258 & 0.105 \\
\hline
\end{tabular}

The GA parameters and variable search range are shown in Tables 9 and 10, respectively.

Table 9. GA parameters.

\begin{tabular}{cc}
\hline Parameter & Value \\
\hline Population size & 100 \\
Number of generations & 500 \\
Crossover probability & 0.7 \\
Mutation probability & 0.1 \\
\hline
\end{tabular}

Table 10. Search range.

\begin{tabular}{cc}
\hline Search Range & Value \\
\hline Rated electric capacity of PGU & {$[0,40]$} \\
Number of photovoltaic cell modules & {$[0,250]$} \\
Electric cooling ratio & {$[0,1]$} \\
Minimum load coefficient of PGU & {$[0.2,1]$} \\
\hline
\end{tabular}

\subsection{Simulation Results Analysis}

Analyzed results are presented according to the optimization flow, based on the simulated annual load data obtained in Jinan. These were obtained in combination with the above parameter settings and in accordance to the optimization of the MATLAB software platform used to solve the equipment capacity and key operating parameters, as shown in Table 11.

The performance values of the optimized configuration are shown in Table 12.

From the above data, we can see that the values of primary energy saving ratio, annual total cost saving rate and carbon emission reduction ratio are $20.94 \%, 11.73 \%$ and $40.79 \%$, respectively. These values fully reflect that the optimization design method can advance the RES-CCHP system in energy conservation, cost saving and emission reduction. Meanwhile, the RES-CCHP system responds to the country's new energy policy, and if the state subsidies are considered, the economic performance will improve. 
Table 11. Optimal results of the RES-CCHP system.

\begin{tabular}{cc}
\hline Item & Value \\
\hline PGU & $20 \mathrm{~kW}$ \\
PV & 220 pieces \\
Absorption chiller & $43 \mathrm{~kW}$ \\
Electric chiller & $26 \mathrm{~kW}$ \\
Boiler & $65 \mathrm{~kW}$ \\
Minimum load coefficient of PGU & 0.26 \\
Electric cooling ratio & 0.2 \\
\hline
\end{tabular}

Table 12. Annual performance value of RES-CCHP system.

\begin{tabular}{cc}
\hline Item & Value \\
\hline Primary energy saving ratio & $20.94 \%$ \\
Annual total cost saving rate & $11.73 \%$ \\
Carbon emission reduction ratio & $40.79 \%$ \\
Mo & $20.66 \%$ \\
\hline
\end{tabular}

In order to further analyze the operating characteristics of the optimally configured RES-CCHP system at different time periods, the indicators of the co-supply system were analyzed on a monthly basis. As shown in Figure 7, the changing trends of the environment and energy indicators were consistent with the economic indicator, thus showing that the overall trends of the lower winter conditions and higher summer conditions. The main reason was attributed to the significant increase of the light intensity in the summer, whereby the output power of the PV had increased significantly. This in turn significantly reduced the amount of electricity purchased by the system and the power generated by the generator set, thereby reducing $\mathrm{CO}_{2}$ emissions and the primary energy consumption.

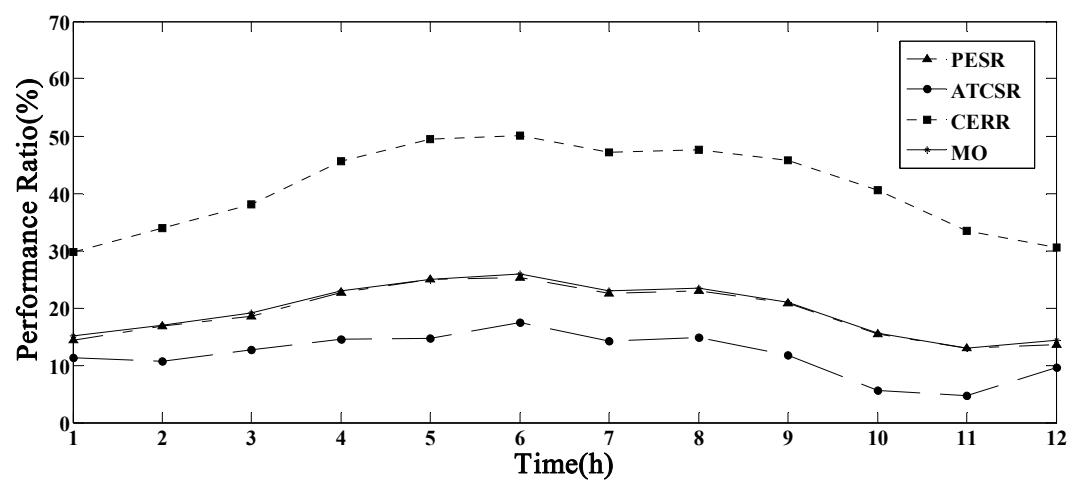

Figure 7. Monthly performance of the RES-CCHP system.

The electric load data of buildings throughout the year is shown in Figure 3. In addition, the electricity consumption of the electric chiller should be considered in the summer. In Figure 8, the green line represents the electricity obtained from the PV, the blue line represents the electricity output of the PGU, and the red line shows the electricity from the grid. During the daytime, especially when the sunlight is particularly strong in the summer, most of the electric load is satisfied by the PV. At the same time, the output of PGU is less. At night, or when the light is weak, it is supplemented by PGU. If the ratio of the required electricity to the rated capacity of PGU is less than the optimized key value $(\theta=0.2)$, the PUG stopped working and all the electricity was provided by the grid. On the contrary, the situation that the required electricity was larger than the rated electrical capacity of PGU will cause the shortfall electricity, and that will occur in the summer days with relatively high cooling demand. The surplus electricity demand will be purchased from the PG. Figure 9 shows the heat distribution of the system. The heat load of the building is represented by the black line, and the blue line is the 
inadequate heat from the boiler which primarily appears in the winter when the heating load exceeds the residual heat of the PGU, while in the summer days, the absorption chiller cannot provide enough cooling load. Concluded from the results, the equipment capacity and operating parameters obtained by using the optimization design method can match efficiently with the energy demands. The system can make full use of solar energy and biomass energy, and can benefit from the time-of-use electricity price, resulting in the reduction of the operating cost.

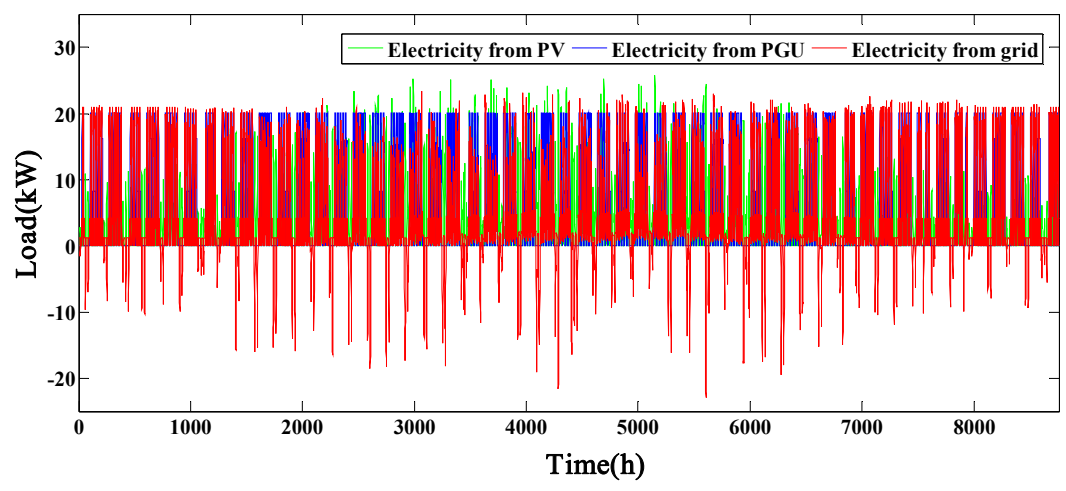

Figure 8. Annual electricity distribution of the RES-CCHP system.

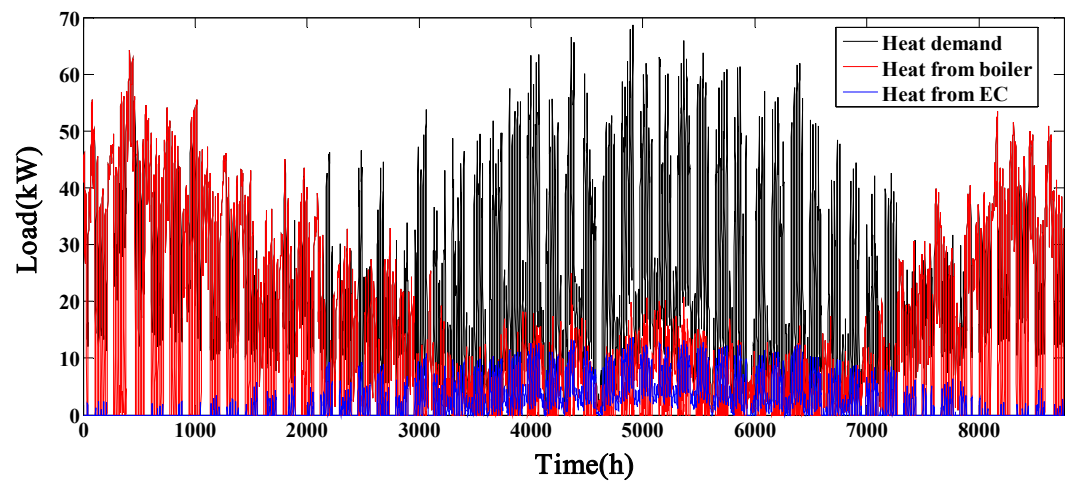

Figure 9. Annual heat distribution of the RES-CCHP system.

\subsection{Sensitivity Analysis}

Since the system designed in this study utilized solar and biomass energy, the randomness and volatility encountered in the process of renewable energy utilization were inevitable (in which biomass can utilize constant temperature fermentation technology to achieve stable gas production). Thus, the climate, and in particular the prediction of the illumination intensity throughout the year, had certain influences on the system design. As shown in Figure 10, the illumination intensity changed from $60 \%$ to $150 \%$ of the test data (shown in Figure 6). Each interval is $10 \%$. It can be seen that the number of optimized PV increased with increasing light intensity, from 159 to 245 . The carbon dioxide emission reduction rate and primary energy saving rate show an increasing trend. Among them, the primary energy saving rate increased from $14.21 \%$ to $29.70 \%$ and the economic indicators increased from $6.17 \%$ to $16.71 \%$. Meanwhile, the rate of reduction of carbon dioxide emissions increased from $39.06 \%$ to $44.07 \%$.

The changes of biogas production will also influence the system performance. Therefore, it is necessary to study how the biogas production affects the system performance. As shown in Figure 11, the daily production of the biogas changed from 140 to $240 \mathrm{~m}^{3} / \mathrm{d}$. Each interval is $10 \mathrm{~m}^{3} / \mathrm{d}$. It can be seen that the three performances show increasing trends when the daily production was less than $200 \mathrm{~m}^{3} / \mathrm{d}$. However, the ATCSR decreased when the daily production exceeded $200 \mathrm{~m}^{3} / \mathrm{d}$. That's because the high daily output that cannot be utilized completely means huge investment. 
Therefore, the fluctuation of the illumination and the changes of biogas production had minor effects on the optimization design method proposed in this study, which shows that the optimization method is robust.

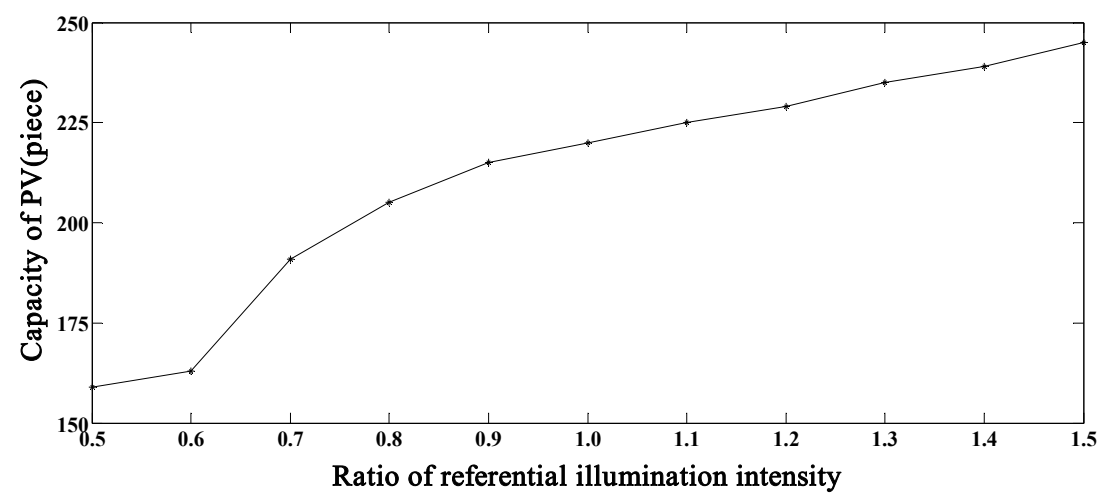

(a)

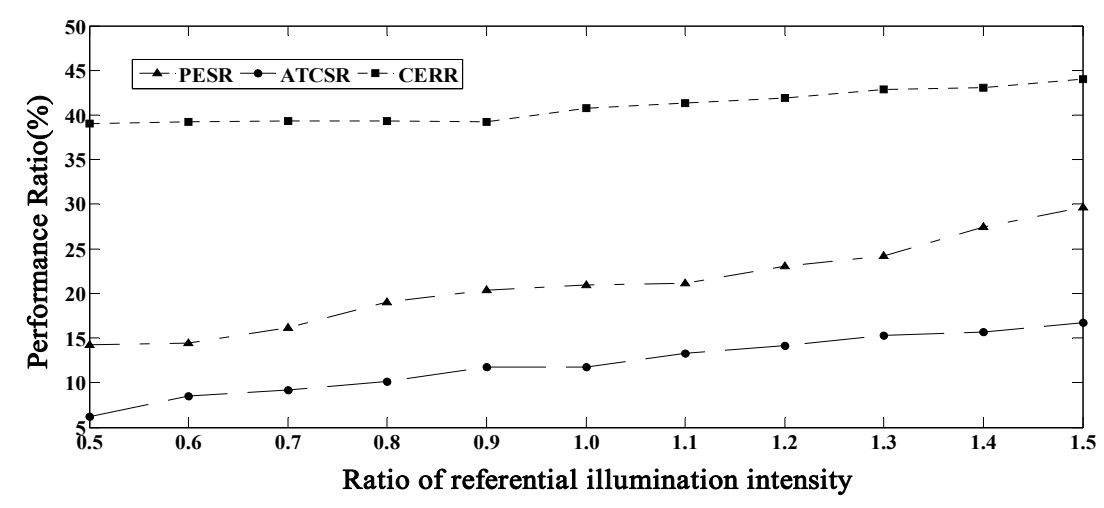

(b)

Figure 10. Sensitivity analyses of illumination intensity. (a) Capacity of photovoltaic (PV) plates; (b) performance ratio.

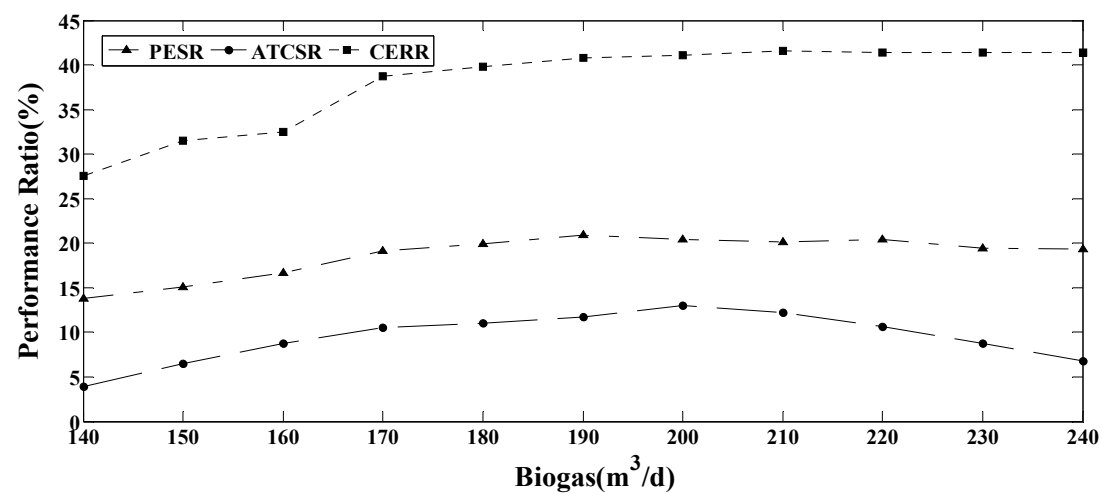

Figure 11. Sensitivity analyses of biogas.

\section{Conclusions}

This study presented a RES-CCHP system driven by a biogas-fueled ICE and PV panels, which capitalized on the respective advantages of the RES and CCHP systems. Comprehensive consideration of renewable energy and load characteristics, four-decision variables (the capacity of power generation unit (PGU), the number of PV panels, the on-off coefficient of PGU, and the ratio of electric cooling to cooling load) were selected to be optimized in order to achieve collaborative optimization. A multi-objective optimization model was proposed that aimed to maximize the PESR, 
ATCSR, and CERR of the RES-CCHP system. Given the proposed optimization model, a GA was adopted to determine the capacity and operation of the RES-CCHP system.

A case study of a small farm in Jinan, China, was conducted to ascertain the feasibility of the proposed RES-CCHP system structure and the corresponding optimal operation strategy. The results illustrated that the implementation of the optimization design was beneficial to energy conservation, cost saving and emission reduction. The values of PESR, ATCSR, and CERR are $20.94 \%, 11.73 \%$ and $40.79 \%$, respectively, which demonstrates the advantages of the RES-CCHP system are clear compared with the SP system. The annual energy distribution results show that equipment capacity and operating parameters obtained by using the optimization design method can match efficiently with the energy demands and reduce the operating cost. Finally, the influences of the volatility of solar energy and the changes of biogas production on the optimization design method are analyzed, which show that the RES-CCHP system and the method proposed are robust.

The RES-CCHP system can effectively stabilize the randomness and volatility of the solar energy and biomass energy through the optimization design proposed in this study. It can significantly improve the energy efficiency and the solar and biomass energy utilization rate, and is suitable for supplying energy to a decentralized rural area.

To capitalize on the advantages of the RES-CCHP system in energy saving and emission reduction, and to improve the economic index, future research will combine the system design optimization and the output plan of key equipment in accordance to load changing, so as to further enhance the system performance.

Author Contributions: L.Z. proposed the idea, performed the experiments and wrote the paper; F.L. analyzed the data; B.S. conceived and designed the experiments, revised the paper; C.Z. supervised the overall work and the overall structure of the paper.

Funding: This research was funded by the National Natural Science Foundation of China (grant numbers 61821004, 61733010, 61320106011, 61573224), and the Young Scholars Program of Shandong University (grant number 2016WLJH29).

Conflicts of Interest: The authors declare no conflict of interest.

\section{Abbreviations}

$\begin{array}{ll}\text { AC } & \text { absorption chiller } \\ \text { ATCSR } & \text { annual total cost saving rate } \\ \text { BCHP } & \text { building cooling heating and power } \\ \text { CCHP } & \text { combined cooling heating and power } \\ \text { CERR } & \text { carbon emission reduction ratio } \\ \text { COP } & \text { coefficient of performance } \\ \text { EC } & \text { electric chiller } \\ \text { EG } & \text { electrical generator } \\ \text { EXH } & \text { exhaust gas } \\ \text { GA } & \text { genetic algorithm } \\ \text { GSHP } & \text { ground-source heat pump } \\ \text { GT } & \text { gas turbine } \\ \text { ICE } & \text { internal combustion engine } \\ \text { JW } & \text { jacket water } \\ \text { LCCA } & \text { life cycle cost analysis } \\ \text { MILP } & \text { mixed integer linear programming } \\ \text { MINLP } & \text { mixed-integer non-linear programming } \\ \text { MO } & \text { multi-objective } \\ \text { NG } & \text { natural gas } \\ \text { NSGA-II } & \text { non-dominated Sort Genetic Algorithm II } \\ \text { RC } & \text { rated capacity } \\ \text { RES } & \text { renewable energy sources } \\ \text { HE } & \text { heat exchanger } \\ & \end{array}$




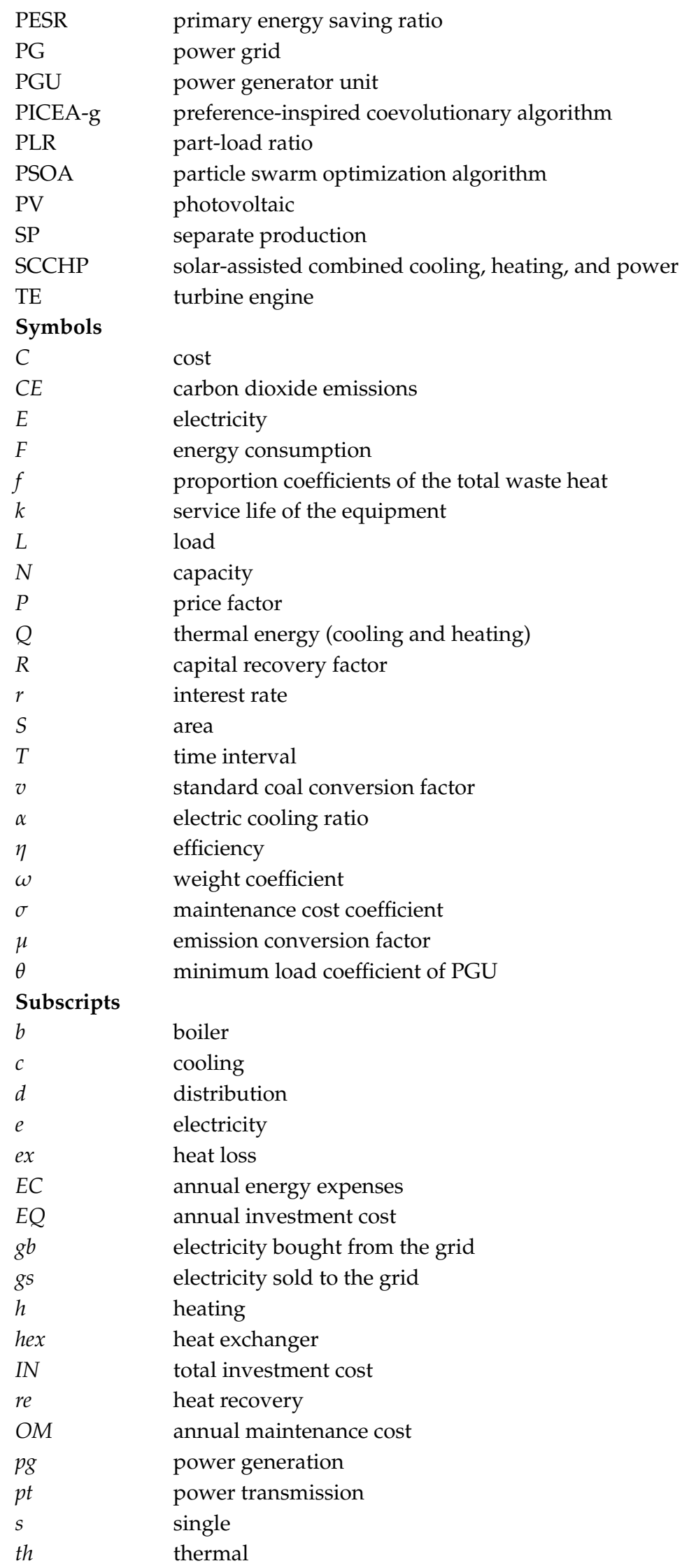




\section{References}

1. Wu, D.W.; Wang, R.Z. Combined cooling, heating and power: A review. Prog. Energy Combust. Sci. 2006, 32, 459-495. [CrossRef]

2. Mancarella, P.; Chicco, G. Assessment of the greenhouse gas emissions from cogeneration and trigeneration systems. Part II: Analysis techniques and application cases. Energy 2008, 33, 418-430. [CrossRef]

3. Cho, H.; Smith, A.D.; Mago, P. Combined cooling, heating and power: A review of performance improvement and optimization. Appl. Energy 2014, 136, 168-185. [CrossRef]

4. Xu, J.; Sui, J.; Li, B.; Yang, M. Research, development and the prospect of combined cooling, heating, and power systems. Energy 2010, 35, 4361-4367. [CrossRef]

5. Gopisetty, S.; Treffinger, P. Generic Combined heat and power (CHP) model for the concept phase of energy planning process. Energies 2016, 10, 11. [CrossRef]

6. Ghaem Sigarchian, S.; Malmquist, A.; Martin, V. Design Optimization of a Small-Scale Polygeneration Energy System in Different Climate Zones in Iran. Energies 2018, 11, 1115. [CrossRef]

7. Wang, J.J.; Yang, K.; Xu, Z.L.; Fu, C. Energy and exergy analyses of an integrated CCHP system with biomass air gasification. Energy 2015, 142, 317-327. [CrossRef]

8. Bellos, E.; Tzivanidis, C. Optimization of a Solar-Driven Trigeneration system with nanofluid-based parabolic trough collectors. Energies 2017, 10, 848. [CrossRef]

9. Li, S.; Sui, J.; Jin, H.; Zheng, J. Full chain energy performance for a combined cooling, heating and power system running with methanol and solar energy. Appl. Energy 2013, 112, 673-681. [CrossRef]

10. Wang, J.; Zhao, P.; Niu, X.; Dai, Y. Parametric analysis of a new combined cooling, heating and power system with transcritical $\mathrm{CO}_{2}$ driven by solar energy. Appl. Energy 2012, 94, 58-64. [CrossRef]

11. Maraver, D.; Sin, A.; Sebastián, F.; Royo, J. Environmental assessment of CCHP (combined cooling heating and power) systems based on biomass combustion in comparison to conventional generation. Energy 2013, 57, 17-23. [CrossRef]

12. Algieri, A.; Morrone, P. Energetic analysis of biomass-fired ORC systems for micro-scale combined heat and power (CHP) generation. A possible application to the Italian residential sector. Appl. Therm. Eng. 2014, 71, 751-759. [CrossRef]

13. Uris, M.; Linares, J.I.; Arenas, E. Feasibility assessment of an Organic Rankine Cycle (ORC) cogeneration plant (CHP/CCHP) fueled by biomass for a district network in mainland Spain. Energy 2017, 133, 969-985. [CrossRef]

14. Maraver, D.; Sin, A.; Royo, J.; Sebastián, F. Assessment of CCHP systems based on biomass combustion for small-scale applications through a review of the technology and analysis of energy efficiency parameters. Appl. Energy 2013, 102, 1303-1313. [CrossRef]

15. Ge, Y.T.; Tassou, S.A.; Chaer, I.; Suguartha, N. Performance evaluation of a tri-generation system with simulation and experiment. Appl. Energy 2009, 86, 2317-2326. [CrossRef]

16. Cao, J. Evaluation of retrofitting gas-fired cooling and heating systems into BCHP using design optimization. Energy Policy 2009, 37, 2368-2374. [CrossRef]

17. Li, M.; Mu, H.; Li, N.; Ma, B. Optimal design and operation strategy for integrated evaluation of CCHP (combined cooling heating and power) system. Energy 2016, 99, 202-220. [CrossRef]

18. Yang, G.; Zheng, C.Y.; Zhai, X.Q. Influence analysis of building energy demands on the optimal design and performance of CCHP system by using statistical analysis. Energy Build. 2017, 153, 297-316. [CrossRef]

19. Wang, F.; Zhou, L.; Ren, H.; Liu, X. Search improvement process-chaotic optimization-particle swarm optimization-elite retention strategy and improved combined cooling-heating-power strategy based two-time scale multi-objective optimization model for stand-alone microgrid operation. Energies 2017, 10, 1936. [CrossRef]

20. Zeng, R.; Li, H.; Liu, L.; Zhang, X.; Zhang, G. A novel method based on multi-population genetic algorithm for CCHP-GSHP coupling system optimization. Energy Convers. Manag. 2015, 105, 1138-1148. [CrossRef]

21. Liu, M.; Shi, Y.; Fang, F. Optimal power flow and PGU capacity of CCHP systems using a matrix modeling approach. Appl. Energy 2013, 102, 794-802. [CrossRef]

22. Wei, D.J.; Chen, A.; Sun, B.; Zhang, C.H. Multi-objective optimal operation and energy coupling analysis of combined cooling and heating system. Energy 2016, 98, 296-307. [CrossRef] 
23. Wang, J.; Zhai, Z.; Jing, Y.; Zhang, C. Particle swarm optimization for redundant building cooling heating and power system. Appl. Energy 2010, 87, 3668-3679. [CrossRef]

24. Yousefi, H.; Ghodusinejad, M.H.; Noorollahi, Y. GA/AHP-based optimal design of a hybrid CCHP system considering economy, energy and emission. Energy Build. 2017, 138, 309-317. [CrossRef]

25. Fani, M.; Sadreddin, A. Solar assisted CCHP system, energetic, economic and environmental analysis, case study: Educational office buildings. Energy Build. 2017, 136, 100-109. [CrossRef]

26. Noussan, M.; Cerino Abdin, G.; Poggio, A.; Roberto, R. Biomass-fired CHP and heat storage system simulations in existing district heating systems. Appl. Therm. Eng. 2014, 71, 729-735. [CrossRef]

27. Gazda, W.; Stanek, W. Energy and environmental assessment of integrated biogas trigeneration and photovoltaic plant as more sustainable industrial system. Appl. Energy 2016, 169, 138-149. [CrossRef]

28. Ameri, M.; Besharati, Z. Optimal design and operation of district heating and cooling networks with CCHP systems in a residential complex. Energy Build. 2016, 110, 135-148. [CrossRef]

29. Ebrahimi, M.; Keshavarz, A. Designing an optimal solar collector (orientation, type and size) for a hybrid-CCHP system in different climates. Energy Build. 2015, 108, 10-22. [CrossRef]

30. Ju, L.; Tan, Z.; Li, H.; Tan, Q.; Yu, X.; Song, X. Multi-objective operation optimization and evaluation model for CCHP and renewable energy based hybrid energy system driven by distributed energy resources in China. Energy 2016, 111, 322-340. [CrossRef]

31. Li, G.Z.; Wang, R.; Zhang, T.; Ming, M.J. Multi-Objective Optimal Design of Renewable Energy Integrated CCHP System Using PICEA-g. Energies 2018, 11, 743. [CrossRef]

32. Wu, J.Y.; Wang, J.L.; Li, S.; Wang, R.Z. Experimental and simulative investigation of a micro-CCHP (micro combined cooling, heating and power) system with thermal management controller. Energy 2014, 68, 444-453. [CrossRef]

33. Wang, J.J.; Jing, Y.Y.; Zhang, C.F. Optimization of capacity and operation for CCHP system by genetic algorithm. Appl. Energy 2010, 87, 1325-1335. [CrossRef]

34. Li, L.X.; Mu, H.L.; Gao, W.J.; Li, M. Optimization and analysis of CCHP system based on energy loads coupling of residential and office buildings. Appl. Energy 2014, 136, 206-216. [CrossRef]

35. Szczypińska, A.; Piotrowski, E.W. Inconsistency of the judgment matrix in the AHP method and the decision maker's knowledge. Physica A 2009, 388, 907-915. [CrossRef]

36. Liu, H.; Ji, Y.; Zhuang, H.; Wu, H. Multi-Objective Dynamic Economic Dispatch of Microgrid Systems Including Vehicle-to-Grid. Energies 2015, 8, 4476-4495. [CrossRef]

37. Zhou, Z.; Liu, P.; Li, Z.; Ni, W. An engineering approach to the optimal design of distributed energy systems in China. Appl. Therm. Eng. 2013, 53, 387-396. [CrossRef]

38. Deng, N.; Cai, R.; Gao, Y.; Zhou, Z.; He, G.; Liu, D.; Zhang, A. A MINLP model of optimal scheduling for a district heating and cooling system: A case study of an energy station in Tianjin. Energy 2017, 141, 1750-1763. [CrossRef]

(C) 2019 by the authors. Licensee MDPI, Basel, Switzerland. This article is an open access article distributed under the terms and conditions of the Creative Commons Attribution (CC BY) license (http:/ / creativecommons.org/licenses/by/4.0/). 